in 0.2 gram doses were used at one time for a couple of weeks, but the general condition seemed to fail so rapidly and the numbness ascended so fast that they were discontinued.

During the last three weeks morphin hypodermatically in 0.016 to 0.032 gram doses were used to produce sleep and alleviate the suffering from cramps in the limbs.

The patient died May 7, 1897, from general asthenia, the end being very quiet.

At the necropsy the suprarenal capsules were found to be almost entirely wasted; what remained was tubercular, as shown by microscopic examination.

The elder brother was a very active business man, having had a responsible position in a wholesale drygoods house. He had typhoid fever and chronic diarrhea in the army, and it troubled him occasionally ever afterward. He suffered from insomnia for several months prior to the establishment of the disease, after which he slept very well; otherwise his previous health had been fairly good.

His first symptom was impaired vision, which gradually progressed until he was unable to read ordinary print; this afterward became considerably better.

The course of his disease was about two years; with the exception of the longer course, and impaired vision, his train of symptoms were about the same as those cited in his brother's case.

There was no necropsy, but a clinical diagnosis of Addison's disease was made by eminent men about a year before his death.

His trouble had been diagnosed as pernicious anemia, neurasthenia, paresis and cancer of the liver, before the correct diagnosis was made.

Conclusions.-Drs. Osler and Quine both say it is the first instance in their knowledge where two cases of Addison's disease have occurred in the same family. Dr. Quine says children of tubercular parents would probably be more susceptible to Addison's disease, but there is no tubercular history in this family. I am informed that these brothers were very similar in habits and temperaments, and this may have something to do with the hereditary element in this instance.

Investigators have come to the conclusion that the suprarenal capsules, in addition to any other functions they may have, elaborate a substance which has a direct action on contractile power of muscular tissue, and on the muscular substance of the coats of the blood vessels, causing contraction and thus heightening the blood pressure. This probably accounts, at least partially, for the great loss of muscular power, this being so great and apparently out of proportion to the other symptoms of the disease.

449 E. 41st Street.

\section{FORCIBLE STRAIGHTENING OF SPINAL CURVATURES DURING COMPLETE ANESTHESIA.}

Read before the Chicago Medical Society, Dec. 23, 1897. BY JOHN RIDLON, M.D.

Professor of Orthopedic Surgery in the Northwestern University Medical Schools; Senior Orthopedic Surgeon to St. Luke's and Michsel Reese Hospitals; Surgeon in Charge of the Home for Destitute Crippled Chlldren: and Consulting Orthopedic Surgeon to the Mary Thompson Hospital for Women and Children. CHICAGO, ILL.

So much has been published during the past two years in the continental medical journals and in the daily newspapers about the new French method of treating Pott's disease that we feel warranted in briefly narrating the facts and in critically discussing this new surgical procedure.

Spinal curvatures are, broadly speaking, of four kinds: 1, simple posterior curvatures; 2, anterior curvatures; 3 , lateral curvatures; and 4 , the posterior curves or angles of spinal caries.

As to the first class of simple posterior curvatures, or the ordinary round shoulders most frequently seen in adolescence and old age, and the posterior curvatures of rachitic infants, nothing so far as I know has been attempted in the way of immediate and forcible straightening under anesthesia.

As to the anterior curvatures, again nothing has been attempted. Indeed cases of this class are seldom met with even by orthopedic surgeons of large experience, and their pathology is not well understood.

As to lateral curvatures of the class ordinarily called "rotary lateral curvatures" or "true lateral curvatures"

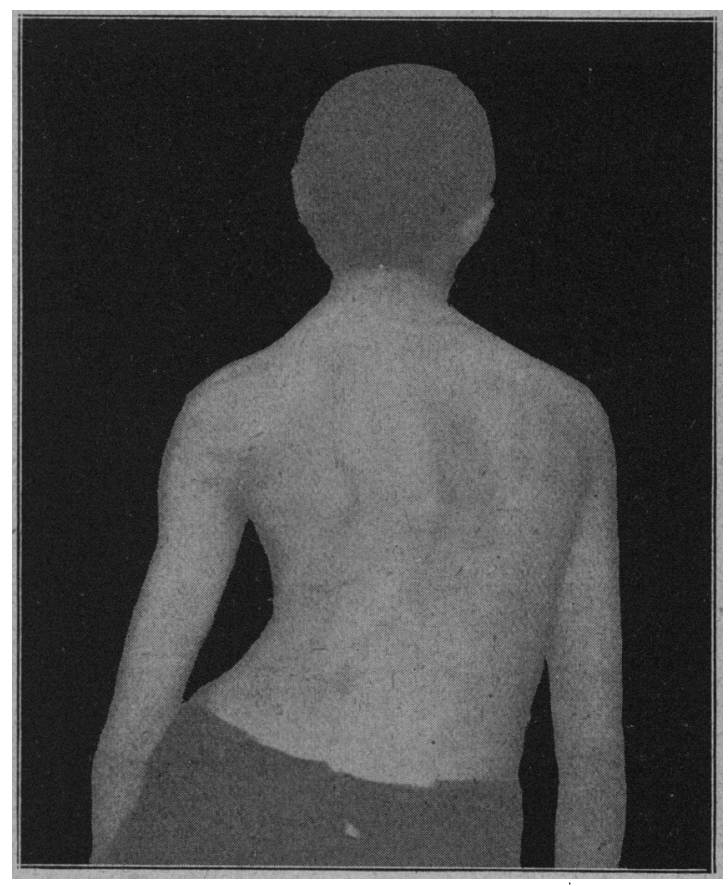

Frg. 1.-A case of scoliosis.

which we orthopedic surgeons denominate scoliosis, I have seen no reports in the medical journals. These cases of scoliosis should be considered as quite apart from postural lateral curvatures and from the lateral curvature, either with or without rotary deformity, which often precedes the posterior deformity of spinal caries and at times accompanies the posterior deform ity in cases of some years standing. Figure 1 shows a well developed case of scoliosis. Figures 2 and 3 show lateral curvature with rotary deformity in a case of spinal caries (tubercular spondylitis) prior to the development of any posterior curve or angle in the spine. Figures 4 and 5 show lateral curvature with rotary deformity in a case of tubercular spondylitis of many years standing and with well marked posterior angular deformity.

I have attempted forcible correction of the deform. ity, under anesthesia, in five cases of scoliosis. Two cases were at Michael Reese Hospital, girls of 14 and 
17 years of age. The curvatures were of the ordinary right dorsal variety, of moderate degree of severity and of several years duration. In each instance I succeeded in reducing the deformity by about one-half. One case at St. Luke's Hospital, a girl of 17 years, with a right dorsal curvature of extreme severity and exceedingly rigid, and of many years duration. In many respects it resembled the case shown in Fig. 1 , but the deformity was greater, the spine was stiffer, the shoulders more displaced to the right, and the deformity of longer duration. I succeeded in reducing the deformity somewhat more than one-third and made the patient taller by an inch and a quarter

The fourth case was at the Home for "Crippled Children. A girl of 15 years with a very severe left

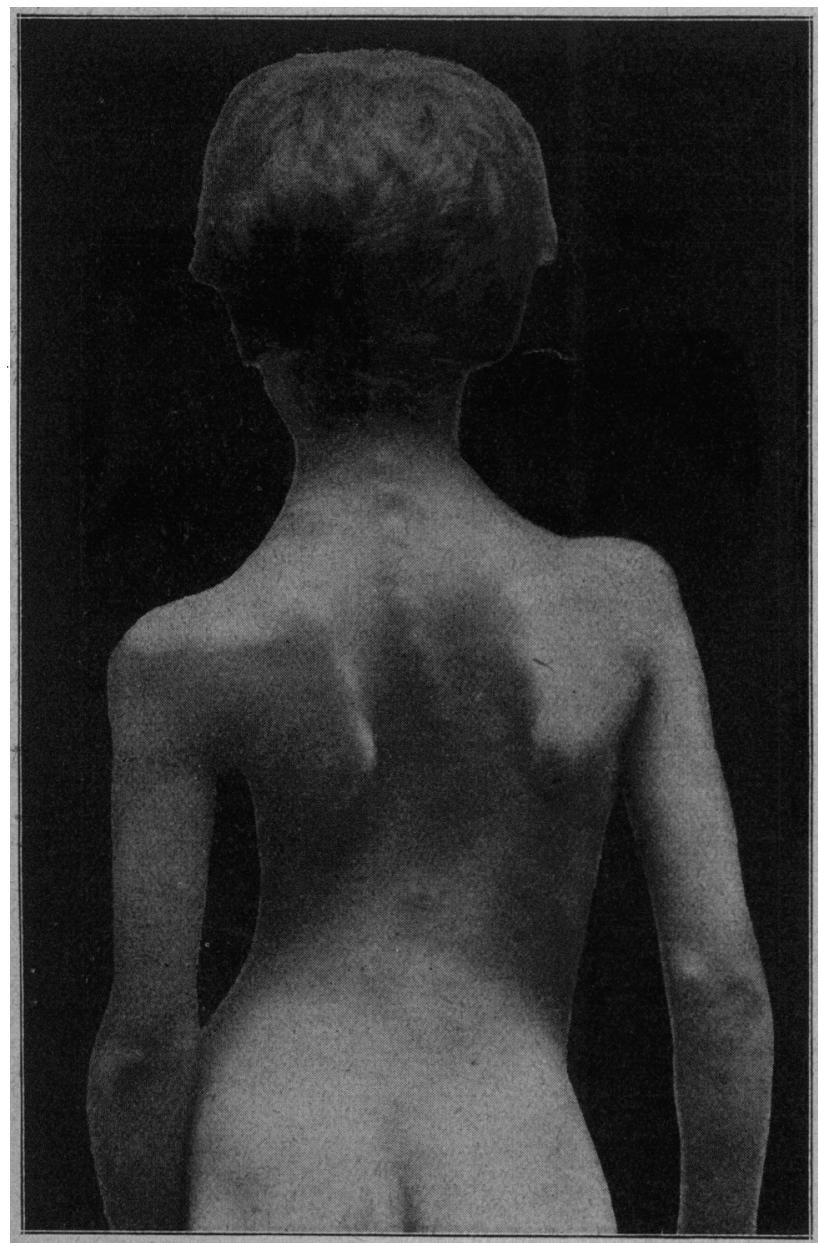

Figs. 2 and 3.-A case of tubercular spondylitis simulating scoliosis shows lateral curvature and rotation deformity.

dorso-lumbar curvature of more than three years duration. Figure 6 shows this case. The pathology is perhaps uncertain. It is a case that most surgeons would unhesitatingly pronounce scoliosis; nevertheless the patient's mother died of consumption; the spine was very stiff for the known duration of the disease; she was not comfortable when lying on her back, and there was pain on pressure over the lower dorsal and lumbar portions of the spine. I do not, even at this time, feel sure as to whether this case is one of tubercular spondylitis or a simple scoliosis.

For nine weeks she was kept in bed with horizontal head-traction of four pounds. The spine became somewhat more flexible, but scarcely straighter. June
23, 1897, under complete anesthesia, I used great force in the way of straightening the curvature. Tearing and crackling sounds were abundant and great straightening resulted. The patient was suspended by the feet and a plaster jacket applied. She was then kept in bed for three weeks, when the operation was again repeated with further gain in the way of straightening. Figure 7 shows this gain, which in height amounts to about three inches.

The fifth case was a girl 7 years old, with wellmarked right dorsal scoliosis. Deformity has been noticed since the child was six months old. The deformity is believed to be rachitic. On Dec. 15 , 1897 at the Home for Crippled Children this curvature was forcibly straightened under anesthesia to

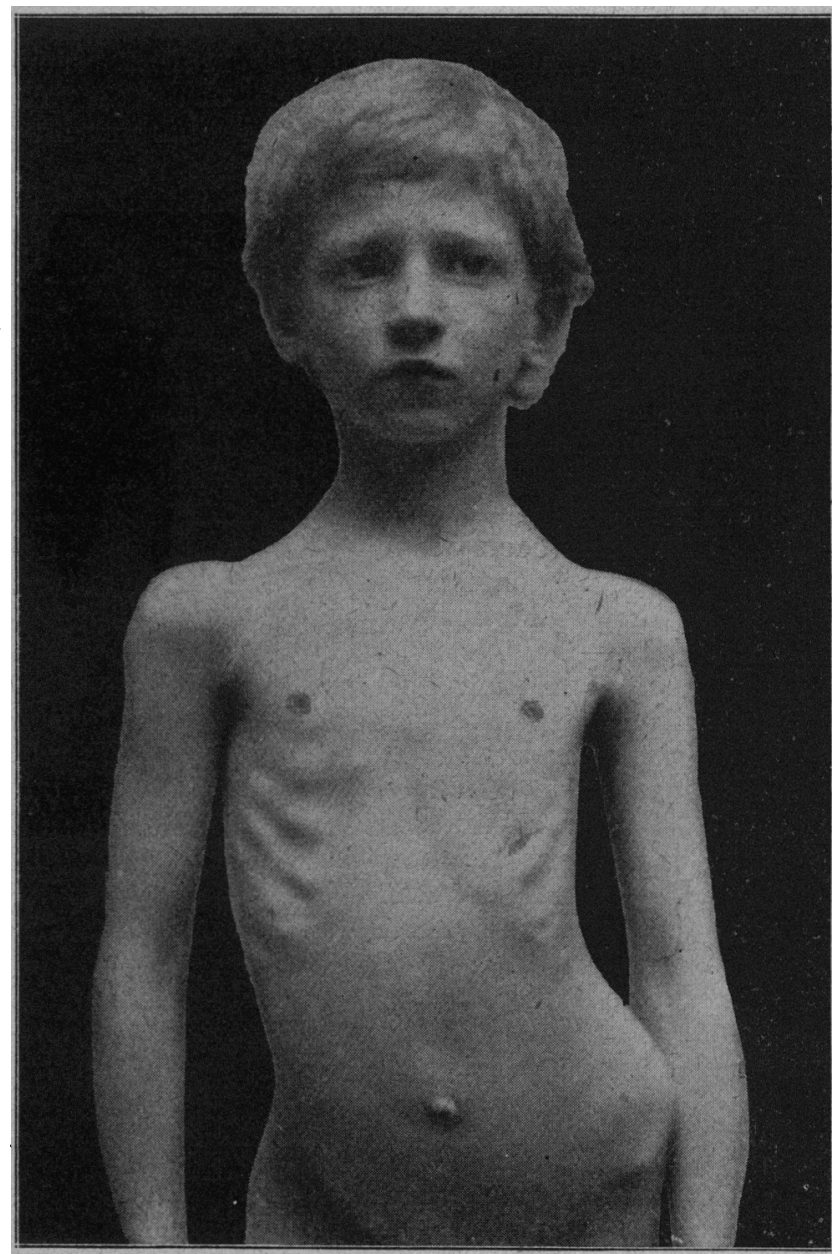

FigURE 3.

about two-thirds its extent. The patient is still in the first plaster jacket, and in bed.

In none of these five cases did any unpleasant symptoms result from the forced straightening.

Finally, as to the posterior curves and angles of spinal caries, that is to say, the deformities of tubercular spondylitis or Pott's disease. It was in this class of cases that the work of forcible straightening under anesthesia was commenced by Dr. Calot, of Berck-sur-Mer. Being dissatisfied with the results obtained by the ordinary methods of treatment, Dr. Calot argued that there appeared no good reason why a tubercular spinal joint should not be treated on precisely the same principles as a tubercular joint in any other part of the body, as the knee or the hip; that 
inasmuch as it is customary to straighten deformities resulting from hip disease and knee disease by forci-

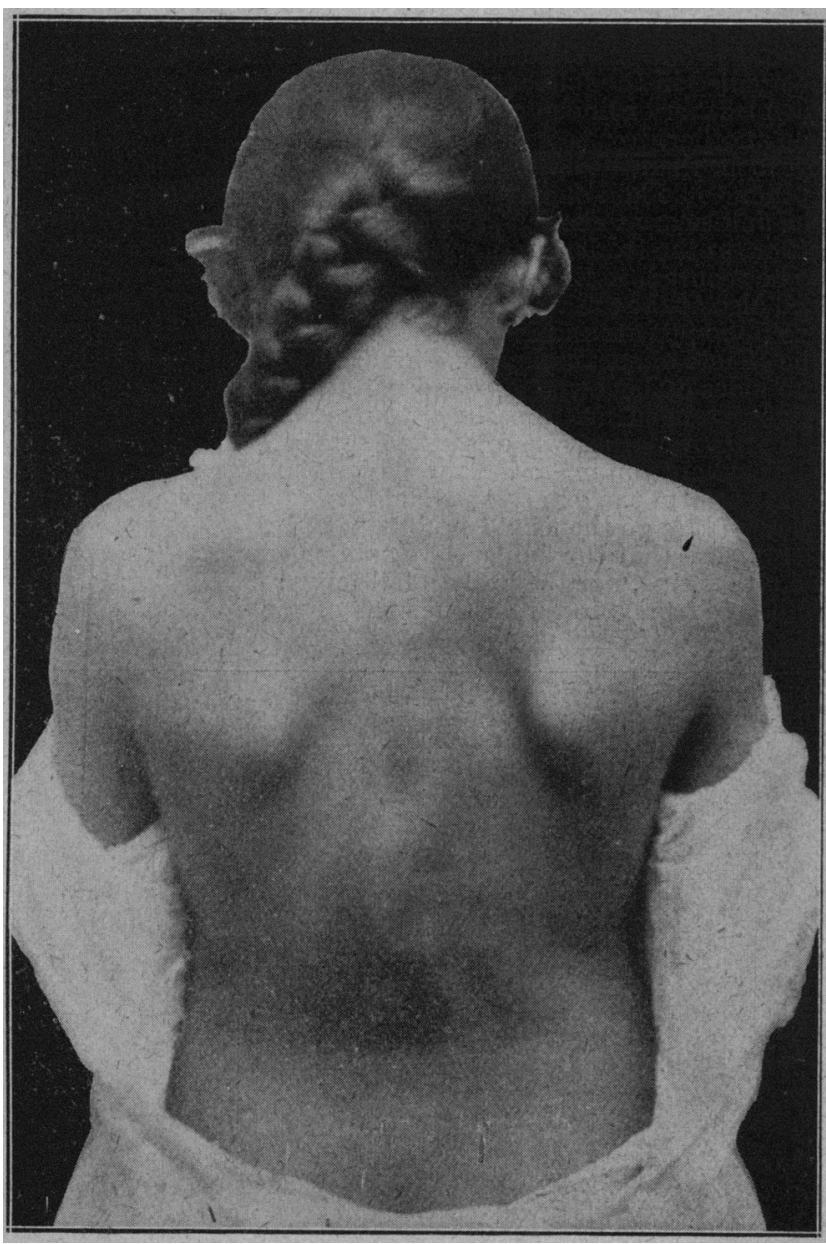

Fir. 4.-An old case of tubercular spondylltis, with posterior, latera and rotary deformity.

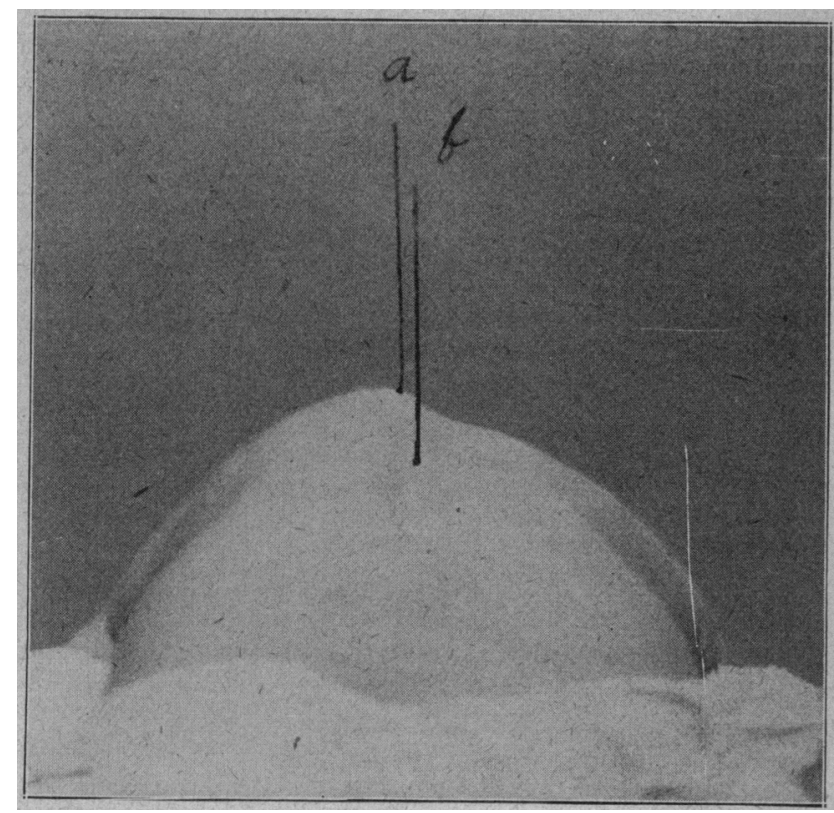

FIG. 5.-The same case shown in Fig. 4. stooping forward, viewed from the rear, showing by the parallel lines, $a$ and $b$, the degree of lateral deviation; showing also the amount of rotary deformity.

ble manipulations under anesthesia, either with or without a cutting operation, it would be perfectly feasible and wholly justifiable to do the same operation for the correction of the deformity resulting from the same disease in the spinal bones and joints.

I do not know just what the "ordinary methods of treatment" were with which Dr. Calot become dissatisfied, but if they were the same that one usually finds in France it is not surprising. Even in this country those surgeons who have depended upon the unqualified surgical instrument maker to measure for and fit braces and those that have placed their reliance upon the plaster jacket as a support in ambulatory cases have hardly been satisfied with the results obtained.

Dr. Calot's methods have been followed, with certain modifications, by many of the continental surgeons. It is not necessary here to name them or

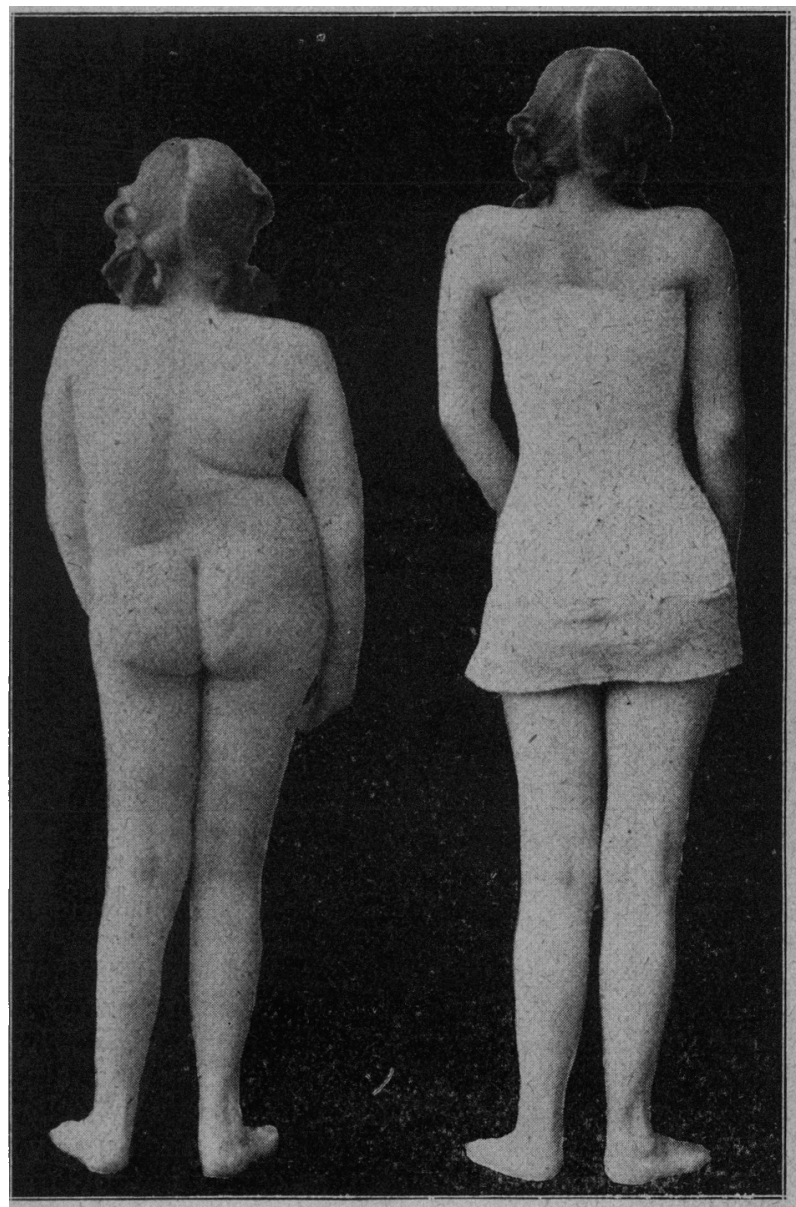

Figs 6 and 7 show case No. 4 of lateral curvature, forced straightening, and four weeks later after second forced straightening.

specify their modifications. Sufficient to say, that in recent cases the straightening was effected by longitudinal (horizontal) traction and counter-traction, by the hands of assistants or by mechanical devices, while the operator made manual pressure in the direction of straightening the kyphosis. In older cases operative measures were added. The soft parts were cut through and the bones divided by chisel in one or more places, abscesses were evacuated and cheesy foci cleaned out when such were accessible; then the deformity was straightened and the spinous processes were wired to each other to maintain the corrected position. Immobilizing dressings were applied, and the patient was kept recumbent in bed for many months. 
This idea of forcibly straightening the kyphosis of Pott's disease did not originate with Dr. Calot, though he may not be aware of the fact. On Dec. 22, 1890, Dr. B. E. Hadra, of Galveston, Texas, straightened a fractured spine and wired the spinous processes. Commenting on the case in the Times and Register, May 23, 1891, he says: "I can not resist the temptation to connect my device also with the treatment of Pott's disease. Here, too, the indication in cases where the abscess or carious bones do not call for other surgical attempts, is mainly to steady the vertebral column in order to protect the cord, to prevent the diseased bones from rubbing on each other, and finally to make the outcome, in regard to disfigurement, as favorable as possible. Judging from my concededly limited experience, and from theoretical deductions, the proposed procedure will do better than braces, corsets, plaster jackets and the like. It seems to me called for as soon as displacement of the bones is noticed; but even if a full kyphosis should be established, it will be proper to put the patient under anesthetic, and to wire to-

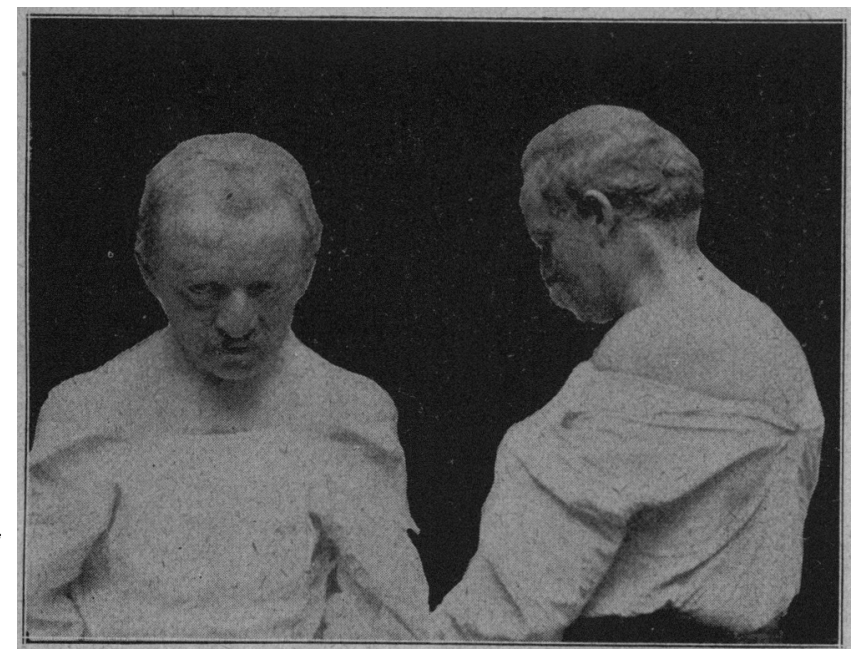

Figure 8 .

Figure

Figs. 8, 9.10 and 11.-Dr. B. E. Hadra's case of wiring the cervical vertebræ. Figs. 8 and 9 show habitual position; Fig. 10 shows the exten to which the chin could be raised; Fig. 11 shows the scar of the operation.

gether the spinous processes, provided that the column can be straightened to a satisfactory extent."

Again in the Medical News, Nov. 28, 1891, Dr. Hadra says, "But if an abscess cavity has already formed, the surgeon will have to decide whether or not its dimensions are too great to be filled up by new bone formation. If the abscess cavity is too large it may be better to allow the diseased surfaces to come in contact and to unite by bony anchylosis with kyphosis. Under such circumstances the wiring will be out of place. Not so, however, if the destruction of the bodies and of the inter-vertebral discs is mod. erate. We may then hope for the reproduction of a sufficient amount of bone, and by holding the spine in a straight line we shall obviously enforce a desirable final outcome."

Forced straightening, without a cutting operation, and without an anesthetic is an idea so old that it has practically been forgotten. Hippocrates writing 500 years B. C. spoke of it as an old method, so old then that the name of the author had been forgotten. $\mathrm{He}$ says:

"Those cases in which the gibbosity is near the neck, are less likely to be benefited by these succussions with the head downward, for the weight of the head and tops of the shoul- ders, when allowed to hang down, is but.small, and such cases are more likely to be made straight by succussion with the feet hanging down, since the inclination downward is greater in this way. When the hump is lower down, it is more likely in this case that succussion with the bead downward would do good. If one then should think of trying succussion, it may be applied in the following manner: The ladder is to be padded with leather or linen cushions, laid across, and well secured to one another, to a somewhat greater extent, both in length and breadth, than the space which the man's body will occupy; he is then to be laid on the ladder upon his back, and the feet at the ankles are to be fastened at no great distance from one another, to the ladder, with some firm soft cord, and he is further to be secured, in like manner, both above and below the knee, and aleo at the nates; and at the loins and chest, loose shawls are to be put around in such fashion as not to interfere with the effects of succussion; and his arms are to be fastened along the sides of his own body and not to the ladder. When you have arranged matters thus, you must hoist up the ladder, either to a high tower, or to the gable end of a house; but the place where you make the succussion should be firm, and those who perform the extension should be well instructed, so that they will let go their hold equally to the same extent, and sud denly, and that the ladder may neither tumble to the ground on either side, nor themselves fall forward. But if the ladder be let go from a tower, or the mast of a ship fastened in the

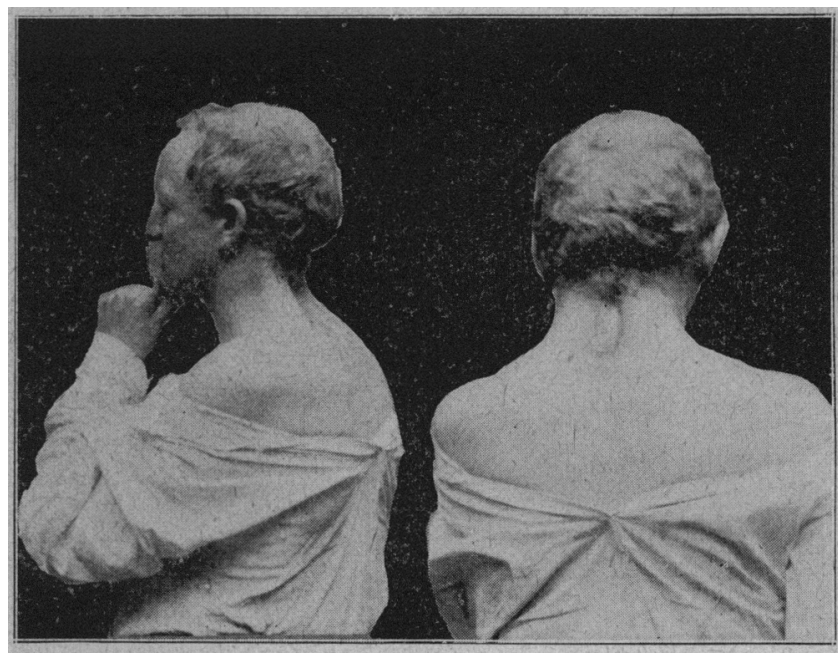

FIGURE 10

FIGURE 11 .

ground with its cordage, it will be still better, so that the ropes run upon a pulley or an axle-tree." (Dr. Adams' translation, Sydenham Ed., and Bigg's "Orthopraxy.")

Hippocrates, however, seems to favor the treatment of gibbosities by extension. Here is his method:

"Something like an oaken bench, of a quadrangular shape, is to be laid along at a distance from the wall [in which there had previously been scooped an oblong furrow], which will admit of persons passing around if necessary, and the bench is to be covered with robes, or anything else which is soft, but does not yield much. The patient after being stoved and bathed with hot water, is to be stretched upon the board upon his face, the arms being laid along and bound to the body. Next the middle of a thong which is soft, sufficiently broad and long, and composed of two cross straps of leather, is to be carried acrose the patient's breast, as near the armpits as possible, then what is over of the thongs at the armpits is to be carried around the shoulders, and afterward the ends of the thong are to be fastened to a piece of wood resembling a pestle; they are to be adapted to the length of the bench below the patient, and so that the pestle-like piece of wood resting against this bench may make extension. Another such bond is applied about the knees and the ankles, and the ends of the thong fastened to a similar piece of wood; and another thong, broad, soft, and strong in the form of a swathe, having breadth and length sufficient, is to be bound tightly about the loins, as near the hips as possible; and then what remains of the swathe-like thong with the ends of the thongs, must be fastened to the piece of wood at the patient's feet, and extension in this fashion is made upward and downward, equally, and at the $\operatorname{same} \operatorname{time}$ in a straight line."

The physician is further recommended to press the 
palm of the hand upon the hump while extension is being made; or a person may sit upon the hump, rising up from time to time, and letting himself fall back upon it. Or a foot may be placed upon the hump and the entire weight of the body brought gradually to bear upon it. Or better still, a lever may be used, one extremity of which is fixed in the hole in the wall (previously scooped out). The lever is brought to bear across the hump, a cushion being interposed, and firmly pressed down while extension is made. (Dr. Adams' translation, and also Bigg's "Orthopraxy.")

Ambroise Pare, in the sixteenth century, followed the teaching of Hippocrates in the essential principles. He made traction and counter-traction by towels, in place of leather thongs, and assistants, in place of the mechanical device; and he discarded the lever, making pressure with his hands, or with " two pieces of wood, four fingers long, and one thick, wrapped more or less in linen cloths, and so to apply one on each side of the displaced vertebræ, and so with your

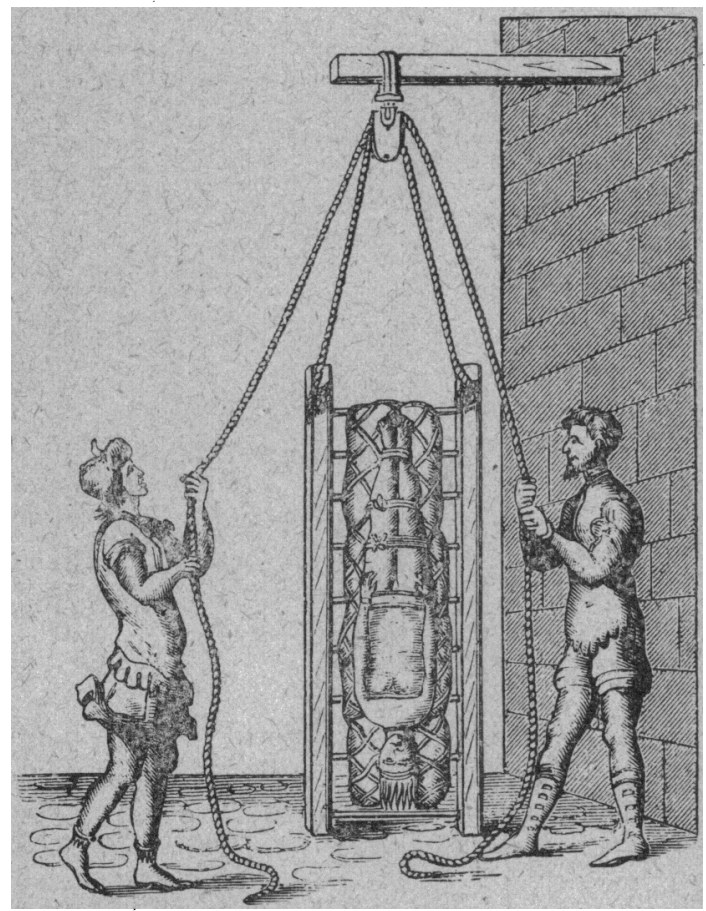

FIG. 12.-The treatment of spinal deformities by succussion. From the Venetian edition of Galen. Quoted in Bigg's "Orthopraxy."

hands to press them against the bunching forth vertebræ, until you force them back into their seats, just after the manner you see before delineated."

It would appear from the above that the only thing new in "the new French method" is the use of the anesthetic, the cutting operation, which is being rapidly abandoned, and the wiring of the spinous processes as recommended by Hadra, which has not yet been demonstrated to be of the slightest value, and appears to add greatly to the discomfort of the patient and to the risk in the treatment of these cases.

European surgeons are becoming more conservative in their work of forcibly straightening spines than they were some months ago, since deaths have occurred from tubercular meningitis and from general tuberculosis arising apparently from dissemination of the disease by tearing through the protecting wall of the tubercular focus, as has occurred after forcible straightening at hip and knee. They are now more inclined to straighten gradually at several sittings instead of attempting to obliterate the deformity at once.

The procedure is as follows: The patient being fully anesthetized, lies face downward upon a table. The hips and the upper portion of the chest may be raised on padded blocks or supported by assistants. Traction is made downward on the legs by assistants or from a girdle around the pelvis by means of some mechanical device, while traction is made upward on the arms and head by assistants or by a girdle around the chest, above the kyphosis, and the aid of some mechanical device. Corrective pressure is brought to bear upon the kyphosis by the hands of the surgeon. When as much correction has been had as is thought safe, some immobilizing device is applied to the spine to maintain the corrected position, usually plaster-of Paris is used. This is applied by some 'while the patient is still horizontal; by others. (Bilhaut and Levassort of Paris) the patient is suspended by the feet during the application of the plaster -dressing. The objections to the prone, horizontal position are that it requires many assistants, favors lordosis above and below the kyphosis, and is a difficult position

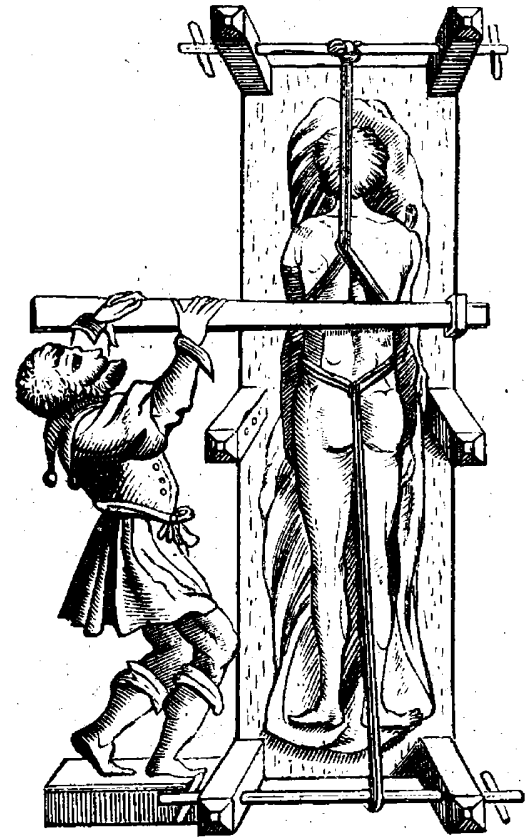

FIG. 18.-Forced correction of spinal curvature by traction and counter-traction, and direct pressure by lever. From the Florentine edition of Galen. Quoted in Bigg's "Orthopraxy."

when the head must be included in the plaster dressing, as it should be when the disease is at or above the ninth or tenth dorsal vertebra. With the patient suspended by the feet fow assistants are necessary, and the head is readily included in the plaster dressing, but suspension by the feet causes the abdominal contents to fall upward against the diaphragm and the jacket constricts uncomfortably when the horizontal posture is resumed.

I have attempted this operation on cases of Pott's disease only seven times. I find parents rather disinclined to submit their children to the operation.

Case 1.-Female, 5 years old, well marked doreal kyphosis (see Fig. 15). The deformity had been present for more than two years, and for the first eighteen months of this period had increased rapidly. No abscess was made. out. On July 15,1897 , at St. Luke's Hospital, the spine was straightened to the extent shown by the second tracing. Horizontal traction and counter-traction was made by two assistants to not more than forty pounds (estimated), and very little direct pressure upon the 
kyphosis was necessary to reduce the deformity to the degree indicated by the tracing. The tracing was made as the patient lay upon the table after traction had been discontinued. A plaster jacket, not including the head, was applied with the patient held horizontal. Immediately afterward the patient stopped breathing ; the jacket was split open, and breathing was resumed. It was left gaping about an inch. Two weeks later when this jacket was removed there was found to be about two-thirds of the original deformity present. The operation was repeated and another jacket was applied, not including the head. At the end of three weeks this jacket was re moved and a pressure sore the size of a dime was found over the most prominent spinous process, and there had been some return of deformity. A jacket well padded with feit to protect the spinous processes was now applied with the patient in the prone horizontal posture and without the administration of an anesthetic. The pressure sore readily healed. The spine was again straightened during anesthesia the patient suspended by the feet and a plaster dressing applied, including the head. The patient is perfectly comfortable and spends much of the day, lying prone and raised on her elbows, in play with toys and the other children.

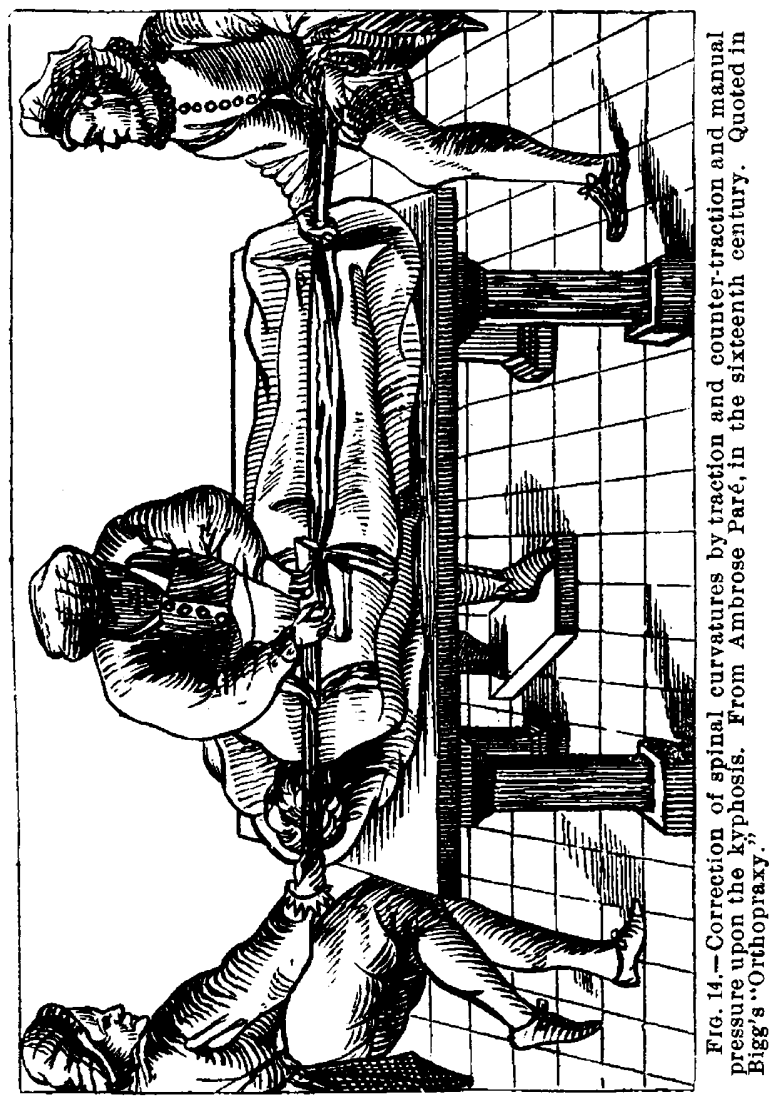

Case 2.-Male, 13 years old, inmate of the Home for Crippled Children, where he has been for four years. There is no history of the case prior to his coming to the Home. During the past four years he has had no treatment, but the deformity has not increased. July 21, 1897, I attempted to straighten this spine under complete anesthesia and in the manner already described. Nothing was accomplished after using as much force as seemed safe.

Case 3.-Female, 4 years old, severe upper dorsal curvature with marked forward projection of the chest. The duration of the deformity is not known. An attempt was made to straighten this case, in the usual way, July 21,1897 , at the Home for Crippled Children. Nothing was gained after using as much force as seemed safe.

In neither of these cases, 2 and 3, were there any unpleasant symptoms as a result of the attempts at straightening.

Case 4.-Male, 4 years old, lumbar kyphosis (see Fig. 16) of one year's standing, complicated with an intra-pelvic psoas abscess that flexed the thigh to a right angle. Tuberculosis in the innther's family. July 21, 1897, at the Home for Crippled Children, this spine was practically straightened (see Fig. 16).

The correction has been maintained, no unpleasant eymptoms have arisen; the psoas abscess has descended upon the anterior and inner aspect of the thigh, and the thigh is now nearly free from flexion deformity. The jacket has been changed without an anesthetic.

Case 5.-Female, 21/2 years old, with lumbar kyphosis of more than six months' duration. The spine was completely straightened at St. Luke's Hospital, Sept. 27, 1897. The jacket has since been changed without an anesthetic, and there is no return of deformity.

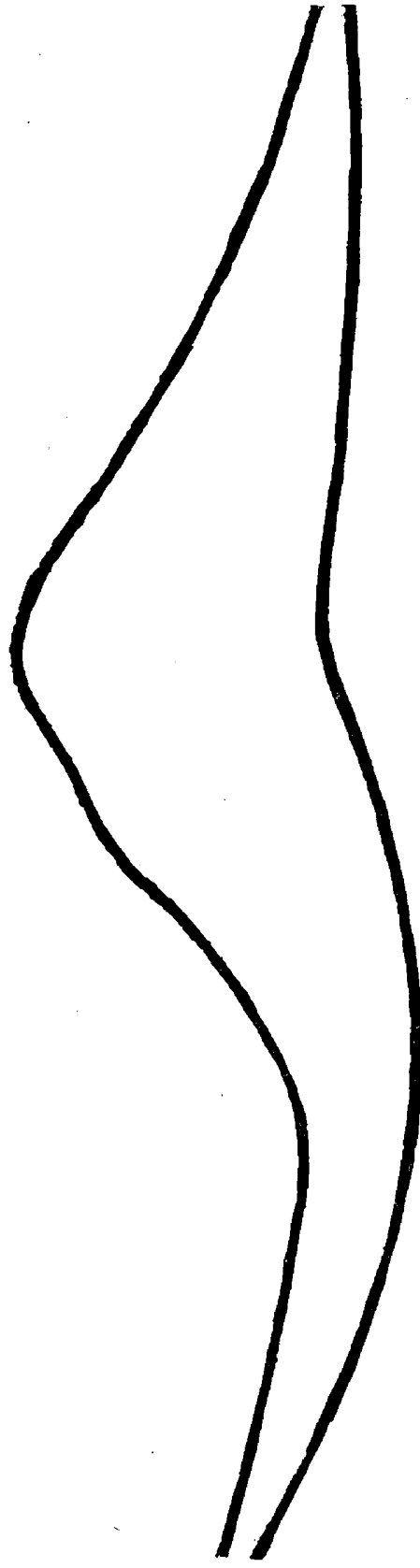

FIG. 15 shows tracing (reduced) of spina curvature before and after straightening in case No. 1.

Case 6.-Boy, 5 years old, left dorso-lumbar curvature of more than three years' duration; very rigid in all directions; muscles rigid in involuntary spasm, and girdle of clonic spasm on any movement or other irritation. Unquestionably a spondylitic deformity, although he has been treated for scoliosis. Dec. 21, 1897, at St. Luke's Hospital, patient under complete anesthesia, three-fourths of the deformity was effaced and patient put up in plaster. There has been increased restless. ness at night, but no increase of conscious pain. The plaster 
Case 7.-Girl, 6 years old, lower lumbar spondylitis with well marked kyphosis of more than two and one-half years' duration. There is a sinus in the left loin, from a lumbar abscess, of some months' standing. Dec. 28, 1897, at St. Luke's Hospital, patient under complete anesthesia, the spine was more than three-fourths straightened, in the usual way.

In none of these cases have there been any un. pleasant symptoms, except as stated in Case 6.

From this slight experience, and from a study of the reports from abroad, I am inclined to the following conclusions:

1. Cases of scoliosis can be safely attempted, and can always be somewhat and often greatly improved by this method of treatment; and no unpleasant results are to be anticipated. It is best to straighten by horizontal traction and counter-traction and by a rotary pressure upon the curvature. During the process of straightening, that is to say, between the operations, patients should wear permanent plaster jackets, extra long, and remain in bed. The jackets will best be put on during suspension from the feet or knees, and complete anesthesia must be maintained until the plaster has set. The feet or knees should be protected from constriction during suspension by plaster stockings applied the day before the operation.

2. In cases of tubercular spondylitis, old cases, where the inflammatory process has ceased and anchylosis has resulted, should be left alone. Any gain in such cases is doubtful, and if accomplished is had at a great risk.

3. Recent cases of tubercular spondylitis can be readily straightened, often at a single operation, and at no greater risk than is encountered in straightening similar deformities at the knee and hip.

4. In older cases of tubercular spondylitis, not yet anchylosed, but in which structural shortening has taken place in the soft parts, repeated efforts at straightening should be made in place of reducing the whole deformity at one sitting.

5 . Plaster jackets are best applied with the patient in the prone horizontal posture in young children. when the deformity is below the ninth or tenth dorsal vertebra; in all other cases it is best to suspend the patient by the feet or knees. In all cases where the disease is at or above the ninth dorsal vertebra the head should be included in the plaster dressing. Pads of felt, at least three-fourths of an inch thick, should be placed on each side of the spinous processes at the region of the disease.

6. All cases should be kept recumbent for a long time, many months, after the spine has been straightened

7. The plaster jacket and the steel brace are found to have the same faults and failings as in their use in acutely progressive cases of spondylitis that have not been subjected to forced straightening, that is to say, they can not be absolutely depended upon to prevent some degree of return of the deformity, and they may cause pressure sores.

8. The dangers from forcible correction of spinal deformities in cases of Pott's disease are tubercular meningitis and general tuberculosis from dissenination of the tubercular infection.

9. The advantages of this method of treatment are obvious: The reduction or abolition of an unsightly deformity; but no. diminution of the duration of th treatment over the ordinary methods by rest and im mobilization is to be anticipated.

\section{ESOPHAGOTOMY FOR THE REMOVAL OF}

A TOOTH PLATE IMPACTED FIVE

DAYS IN THE UPPER THIRD

OF THE ESOPHAGUS.

Presented to the Sectiou on Laryngology and Otology, at the Forty eighth Annual Meeting of the American Medical Association, at Philadelphia, Pa., June 1-4, 1897.

BY JOHN O. ROE, M.D. ROCHESTER, N. Y.

On Saturday, March 28, 1896, as I returned to the city after an absence of two days, I found Elisha L. Gates, a man of 66 years, impatiently awaiting me, and complaining of a difficulty in swallowing and of a severe pain in the neck.

I elicited from his attendant the following history of the trouble: On the previous Monday evening, while eating his dinner, his tooth-plate, which was an upper one, slipped into his throat and passed down into his esophagus. At the time, he choked but little and coughed only two or three times. He stated to those present that he had swallowed his plate, and in evidence called attention to a lump in his neck. The family physician was called soon after, but found no lump in his neck other than the pomum Adami, and as he could swallow liquids without difficulty and complained of no pain in his neck, but of soreness in his abdomen, the doctor concluded that the plate had passed into his stomach.

There was no change in the patient's condition until the following Thursday night, when he began to expectorate freely. The lower portion of his throat was also somewhat painful and obstructed, but as he was still able to swallow liquids freely and the only pain complained of was in his epigastrium, it was still believed that the disturbance was caused by the toothplate in the stomach.

On Friday the pain in the lower part of his throat and in the neck became quite severe and he could swallow no solids whatever, and liquids in small quantities only. The family physician was again called and then concluded that the plate must be lodged in the esophagus instead of the stomach, and referred the patient to me. He came to my office, but finding that I would not return until the following day, went home and awaited my arrival, the doctor seeing nothing more of him.

On examining his throat with a sound, I found an obstruction in the upper third of the esophagus, just below the cricoid body. This was evidently the tooth plate. 'I then endeavored to extract it. I could readily grasp the plate with a pair of esophageal forceps, but it was so firmly fixed that the amount of force necessary to extract it would certainly have lacerated the esophagus. It was therefore deemed imprudent to attempt its extraction in this manner. I endeav. ored, however, to turn it up by means of an esophageal hook, but it was impossible in any manner to dislodge it. It was apparent, therefore, that esophagotomy must at once be resorted to.

I sent him to the hospital and early in the evening the operation was performed, Drs. Mulligan, W. R. Howard, Soble, Rose, and the hospital internes being present. An incision was first made in the left side of the neck, which was carefully dissected down until the esophagus was reached. An esophageal sound was then passed through the mouth and the wall raised over the tooth-plate to facilitate the incision of the esophagus. This was made in the side of the 